\title{
Does Platelet-rich Plasma Augmentation Following Hip Arthroscopy Improve Outcomes: A Systematic Review
}

\author{
Mohammed Ali, MBBS, MRCS, MD, Biju Benjamin, MBBS, MRCS, MD, \\ Nimesh Jain, MBBS, MRCS, MD*, Ajay Malviya, MD ${ }^{+}$ \\ Department of Trauma and Orthopaedics, Raigmore Hospital, UK, \\ North Cumbria NHS Foundation Trust, Carlisle, UK*, \\ Northumbria Healthcare NHS Foundation Trust, North Shields, UK
}

Platelet-rich plasma (PRP) has gathered widespread acceptance among orthopaedic surgeons because of its multimodal effects on tissue healing. Varying results have been reported when PRP injections are combined with hip arthroscopic surgery. To evaluate the influence of PRP on clinical outcomes following hip arthroscopy. We hypothesized that patients treated with PRP would have improved postoperative outcome scores. A search of the National Institute for Health and Care Excellence (NICE) healthcare database advanced search (HDAS) via Athens (PubMed, MEDLINE, CINAHL, EMBASE, and AMED databases) was conducted from their years of inception to May 2018 with the keywords: "Hip Arthroscopy" and "Platelet-Rich Plasma". A quality assessment was performed based on the Cochrane risk of bias tool. Three studies were included for analysis; two of which had low risk of bias. The studies included 363 hips, of which 141 were randomised for PRP treatment. The mean age of all patients was 35 years and the follow-up ranged from 18.5 to 36 months. Authors used different PRP systems and preparations. Modified Harris hip score was reported in all three studies with two studies favouring the use of PRP. The use of PRP following hip arthroscopy did not lead to significantly improved postoperative pain or functional outcomes when compared to control groups in the studies included in this review.

Key Words: Platelet-rich plasma, Labral repair, Hip joint, Young adult

Submitted: February 22, 2020 1st revision: February 25, 2020

Final acceptance: February 26, 2020

Address reprint request to

Mohammed Ali, MBBS, MRCS, MD

(https://orcid.org/0000-0003-0012-0451)

Department of Trauma and Orthopaedics, Raigmore Hospital, Old

Perth Rd, Inverness IV2 3UJ, UK

TEL: +44-1463704000 FAX: +44-1463704000

E-mail: Mohammed.ali17anhs.net

This is an Open Access article distributed under the terms of the Creative Commons Attribution Non-Commercial License (http://creativecommons. org/licenses/by-nc/4.0) which permits unrestricted non-commercial use, distribution, and reproduction in any medium, provided the original work is properly cited.

\section{INTRODUCTION}

Hip chondral defects or injuries and labral tears are common sources of hip pain. Also, femoroacetabular impingement has been implicated in the development of osteoarthritis of hip. Recently, there have been remarkable advances leading to earlier diagnosis and management of intraarticular hip pathologies ${ }^{1}$. Hip conservation surgeries, particularly arthroscopic hip surgery, have increased in importance and demonstrated consistent and sustained benefits, however, there is a subset of patients treated in this manner for whom symptoms persist ${ }^{2}$. Arthroscopic interventions may themselves initiate inflammatory responses that may result in undesired 
and unforeseen outcomes. An improved understanding of healing mechanisms and platelet-rich plasma (PRP) therapies has provided opportunities for combining mechanical and biological concepts to treat compromised clinical conditions, such as avascular necrosis of the femoral head ${ }^{3}$, chondral defects $^{4)}$, and labral tears ${ }^{5}$.

PRP has gathered widespread acceptance among orthopaedic surgeons because of its multimodal effects on tissue healing ${ }^{6}$. It is postulated that PRP enhances musculoskeletal healing by providing an increase in the concentration of platelets to beyond physiological levels, thereby providing a higher concentration of growth factors (e.g., platelet-derived endothelial growth factor, plateletderived growth factor, transforming growth factor, insulinlike growth factor, vascular endothelial growth factor, basic fibroblast growth factor $)^{5}$. Moreover, PRP has been proven to stimulate angiogenesis through activation of PRPreleasate $^{7}$. Recently, PRP has been increasingly utilized as a minimally invasive approach to enhance tissue healing in different conditions (e.g., rotator cuff repair ${ }^{8,9)}$, patellar tendinopathy ${ }^{(0)}$, knee osteoarthritis ${ }^{11)}$, lateral epicondylitis ${ }^{12)}$, osteochondral lesions of the talus ${ }^{13)}$, anterior cruciate ligament [ACL] reconstruction ${ }^{14}$, hip osteoarthritis ${ }^{15)}$. Studies of PRP injection in patients who received hip arthroscopic surgery to treat femoroacetabular impingement have reported varying results ${ }^{16-18)}$.

\section{AIM}

To evaluate the influence of PRP on clinical outcomes in patients who had undergone hip arthroscopic surgeries for labral repair. We hypothesized that patients who received hip arthroscopic surgeries treated with PRP would have improved postoperative outcomes.

\section{METHODS}

A systematic review of the literature was conducted according to the Preferred Reporting Items for Systematic Reviews and Meta-Analyses (PRISMA) guidelines with a PRISMA Checklist and algorithm ${ }^{19}$. All studies that met the following criteria were included: (i) patients underwent hip arthroscopy for labral repair; (ii) PRP was used as an augmentation treatment; (iii) there was a minimum followup of 12 months; and (iv) studies were randomized controlled trials or cohort studies with a comparative control group. Studies that did not use PRP as augmentation in hip arthroscopy or used PRP with other surgical procedures were excluded. We assessed each article for reported outcome measures with the primary outcome of interest the modified Harris hip score. Secondary outcomes of interest (when available) included the: (i) visual analogue scale (VAS); (ii) non-arthritic hip score (NAHS); (iii) hip outcome score-activities of daily living (HOS-ADL); and (iv) hip outcome score-sport-specific subscale (HOS-SSS).

A detailed search of the National Institute for Health and Care Excellence (NICE) healthcare database advanced search (HDAS) via Athens (PubMed, MEDLINE, CINAHL, EMBASE and AMED databases) was conducted from their years of inception to May 2018. Two independent reviewers (MA \& NJ) separately conducted the search. A structured search strategy was used to access both published and unpublished work. The key words used were: (i) hip arthroscopy; (ii) femoroacetabular impingement; (iii) labral tear; (iv) platelet-rich plasma; and (v) modified Harris hip score. We used the Boolean operator 'OR' and subsequently 'AND' to consolidate the search results.

Articles were initially screened for relevance by title and abstract. We obtained the full-text article if the abstract did not allow the investigators to assess the defined inclusion and exclusion criteria. A cross-reference search of selected articles was performed to obtain other relevant articles. Two independent investigators (MA \& NJ) separately assessed each article that met inclusion criteria. Any discrepancies were resolved by discussion to reach a consensus; if disagreement persisted, an independent third reviewer (AM) was conferred. All articles had to be published in peer-reviewed journals. Case reports, conference abstracts, posters, studies on animals, cadavers or in vitro, instructional course lectures and letter to editors were excluded.

Relevant data from articles which met the inclusion criteria were included after assessment of full text. All data related to study methodology, patient demographics, type of injury, treatment methods, and related outcomes and complications were included. Data extraction was separately undertaken by two independent reviewers (MA $\& \mathrm{NJ}$ ) using a standardized data-collection form formulated after discussion and undertaking pilot data collection. Missing data pertaining to these parameters were excluded from this systematic review. The methodological quality of studies included in review randomized controlled trials were later assessed for risk of bias using the Cochrane risk-of-bias tool ${ }^{20}$. The use of the risk-of-bias tool is explained in the Cochrane handbook ${ }^{21)}$ and includes assessment of the following domains: (i) sequence generation; (ii) allocation concealment; (iii) blinding of participants and personnel; 


\section{Hip \& Pelvis}

Hip Pelvis 32(2): 70-77, 2020

(iv) blinding of outcome assessors; (v) incomplete outcome data; (vi) selective outcome reporting; and (vii) other sources of bias. Continuous variables were reported as means plus standard deviation or ranges. The categorical variables were reported as frequency or percentages. Weighted mean differences were used to analyse continuous outcomes in terms of range of motion and functional outcomes (if they were reported in two or more studies) and standardized mean difference for outcomes reported in all studies. A $P<0.05$ was considered statistically significant. The standard deviations were not reported in some studies, therefore $P$-values were used to compute the standard error for the difference of the means, followed by calculation of standard deviation and finally mean differences were derived from the same. RevMan 5.3 (https://training.cochrane.org/ online-learning/core-software-cochrane-reviews/revman) was used to summarize the findings of controlled studies using random effect models.

\section{RESULTS}

A total of 27 articles were identified through the search engine. Removal of duplicates after eligibility screening yielded 15 studies. Following screening of titles and abstracts, three articles were identified that fulfilled all criteria as predetermined and were considered for final analysis. The study selection process is summarized in the PRISMA flow diagram (Fig. 1).

Among these, two studies were randomized controlled trials ${ }^{16,18}$ and the other was a quasi-randomized controlled trial $^{17)}$. All three studies were published between 2014 and 2015.

\section{Demographics}

A total of 408 patients were included in the reviewed studies; 45 patients were lost to follow-up and 363 patients were available for final analysis. Of these, 141 patients were treated with PRP injections following hip arthroscopy, 35 were in an untreated control group and 180 were in a comparative group in one study. The mean age of patients was 35 years old (16-63 years). The duration of follow-up ranged from 18.5 months to 36 months. The sex distribution was reported in 328 patients (61 males and 100 females in

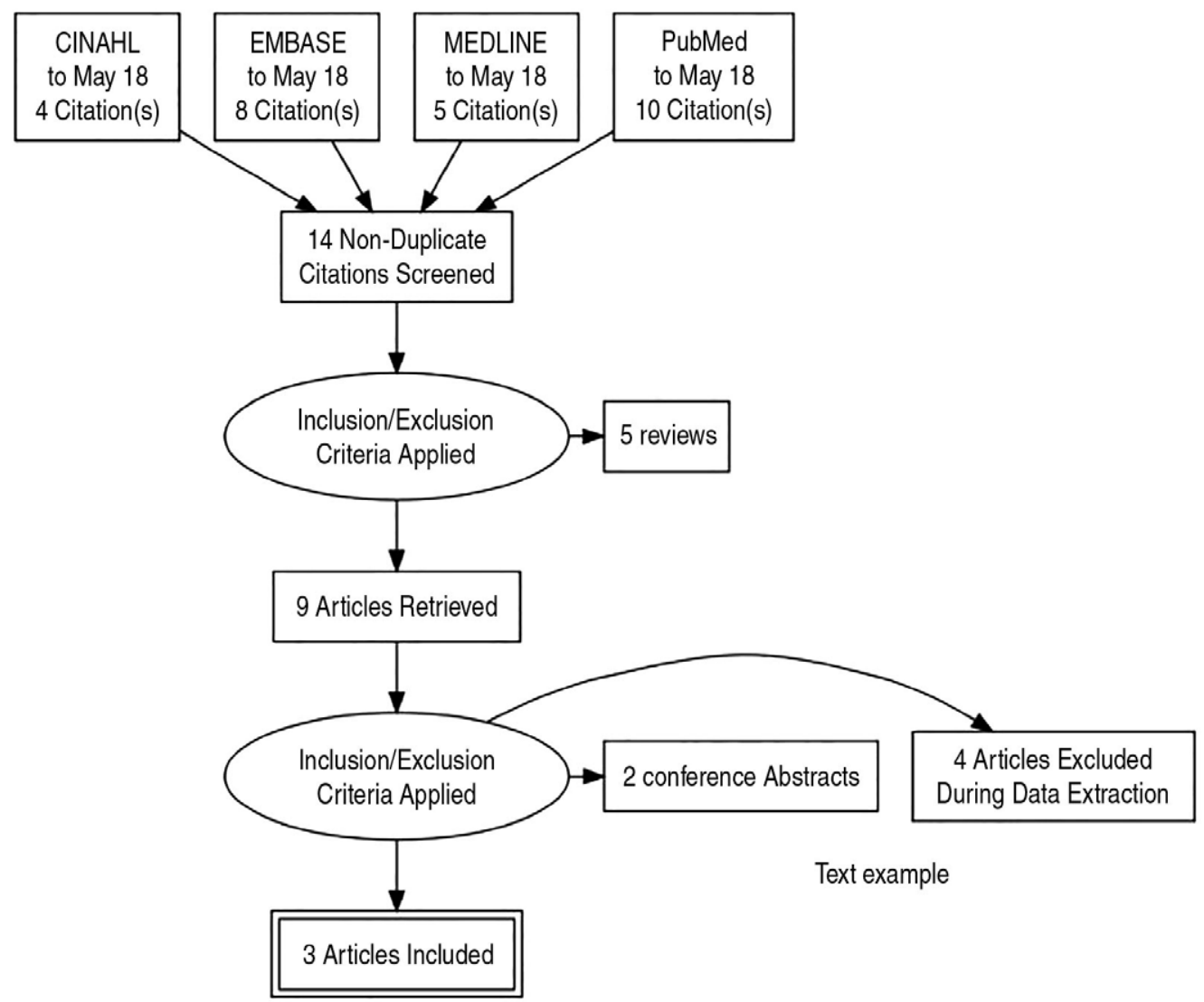

Fig. 1. Preferred Reporting Items for Systematic Reviews and Meta-Analyses (PRISMA) flow diagram. 
Mohammed Ali et al. Does PRP Augmentation Following Hip Arthroscopy Improve Outcomes

the PRP group). The distribution by sex of the 35 patients in one study was not provided (Table 1).

\section{Platelet-rich Plasma Protocols}

All three included studies used different PRP protocols (Table 2). The used PRP systems, volume of blood withdrawn, volume of PRP injected and method of administration are described in Table 2.

\section{Outcome Measures}

Both clinical and functional outcome were evaluated (Table 3).

\section{Modified Harris Hip Score}

Modified Harris hip score was reported in all three studies. The weighted mean for modified Harris hip score at final follow-up was 82.15 in the PRP groups compared to 83.99 in the comparison groups (control/bupivacaine); no significant differences between the two groups at final follow-up was observed. The modified Harris hip score was better in the PRP group in one study (97.1 vs. 94.76), and better in the control group in the other two studies (78.6 vs. 82.6 and 75.9 vs. 81.3), However the differences were not statistically significant (Fig. 2, 3).

\section{Other Outcome Scores}

The visual analogue scale was reported in two studies.

Table 1. Description of Included Articles

\begin{tabular}{|c|c|c|c|c|c|c|c|c|}
\hline Study & $\begin{array}{l}\text { Level of } \\
\text { evidence }\end{array}$ & Diagnosis & No. of hip & $\begin{array}{c}\text { Mean } \\
\text { age (yr) }\end{array}$ & $\begin{array}{c}\text { Mean FU } \\
\text { duration (mo) }\end{array}$ & $\begin{array}{l}\text { Sex (male/ } \\
\text { female) (n) }\end{array}$ & $\begin{array}{l}\text { Outcome } \\
\text { measure }\end{array}$ & Complication \\
\hline $\begin{array}{l}\text { Rafols et al. } \\
\text { [16] (2015) }\end{array}$ & II & $\mathrm{FAl}$ & 57 (30 PRP) & 35 & $24-36$ & $30 / 27$ & VAS, mHHS & None reported \\
\hline $\begin{array}{l}\text { Redmond et al. } \\
\text { [17] (2015) }\end{array}$ & II & $\begin{array}{l}\text { Labral } \\
\text { tears }\end{array}$ & $\begin{array}{c}271 \text { (91 PRP, } 80 \\
\text { bupivacaine) }\end{array}$ & 36 & 24 & $31 / 73$ & $\begin{array}{c}\text { mHHS, VAS, } \\
\text { NAHS, to THR } \\
\text { HOS-ADL }\end{array}$ & $\begin{array}{l}2.9 \% \text { conversion } \\
10.6 \% \text { underwent } \\
\text { revision surgery }\end{array}$ \\
\hline $\begin{array}{l}\text { LaFrance et al. } \\
\text { [18] (2015) }\end{array}$ & I & FAl & $\begin{array}{l}35 \text { (20 PRP, } \\
15 \text { placebo) }\end{array}$ & 34 & 18.5 & $\begin{array}{l}\text { Not } \\
\text { reported }\end{array}$ & $\begin{array}{c}\text { NAHS, mHHS, } \\
\text { HOS-ADL }\end{array}$ & $\begin{array}{l}\text { Bruising and } \\
\text { swelling }\end{array}$ \\
\hline
\end{tabular}

FU: follow-up, FAl: femoroacetabular impingement, PRP: platelet-rich plasma, VAS: visual analogur scale, mHHS: modified Harris hip score, NAHS: non-arthritic hip score, THR: total hip replacement, HOS-ADL: hip outcome score-activities of daily living.

Table 2. PRP Systems Used by Authors

\begin{tabular}{|c|c|c|c|c|c|}
\hline Study & PRP system & $\begin{array}{l}\text { Blood } \\
\text { draw }\end{array}$ & $\begin{array}{l}\text { Volume } \\
\text { of PRP }\end{array}$ & PRP preparation & Method of administration \\
\hline $\begin{array}{l}\text { Rafols et al. } \\
\text { [16] (2015) }\end{array}$ & $\begin{array}{c}\text { GPS III (Biomet, } \\
\text { Warsaw, IN, USA) }\end{array}$ & $55 \mathrm{~mL}$ & $6 \mathrm{~mL}$ & $\begin{array}{c}7.3 \text { to } 8.3 \text { times greater than } \\
\text { whole blood. The average } \\
\text { concentrations of RBC and } \\
\text { WBC are } 96.4 \times 10^{3} / \mathrm{mm}^{3} \text { and } \\
275.4 \times 10^{3} / \mathrm{mm}^{3} .\end{array}$ & $\begin{array}{l}6 \mathrm{~mL} \text { of PRP was infiltrated } \\
\text { intraoperatively under } \\
\text { arthroscopic visualization } \\
\text { (without water) at the end of } \\
\text { the operation. }\end{array}$ \\
\hline $\begin{array}{l}\text { Redmond et al. } \\
\text { [17] (2015) }\end{array}$ & $\begin{array}{c}\text { Arthrex (Naples, } \\
\text { FL, USA) }\end{array}$ & $16 \mathrm{~mL}$ & $\begin{array}{l}4 \text { to } \\
7 \mathrm{~mL}\end{array}$ & $\begin{array}{l}\text { Two times higher than } \\
\text { that of whole blood with } \\
\text { no leukocytes. }\end{array}$ & $\begin{array}{l}\text { Administration was performed } \\
\text { after wound closure by a spinal } \\
\text { needle that was placed } \\
\text { previously under arthroscopic } \\
\text { visualization at the } \\
\text { capsulotomy site. }\end{array}$ \\
\hline $\begin{array}{l}\text { LaFrance et al. } \\
\text { [18] (2015) }\end{array}$ & $\begin{array}{l}\text { Accelerate } \\
\text { (Exactech Biologics, } \\
\text { Gainesville, FL, USA) }\end{array}$ & $52 \mathrm{~mL}$ & $5 \mathrm{~mL}$ & $\begin{array}{c}7 \text { to } 10 \text { times greater than } \\
\text { whole blood. Leukocytes } \\
\text { concentration increased } \\
\text { over baseline. }\end{array}$ & $\begin{array}{l}\text { Joint was evacuated of any } \\
\text { residual fluid. Patients then } \\
\text { underwent an intra-articular } \\
\text { injection of } 5 \mathrm{~mL} \text { of PRP. }\end{array}$ \\
\hline
\end{tabular}

PRP: platelet-rich plasma, RBC: red blood cell, WBC: white blood cell. 


\section{Hip \& Pelvis}

Hip Pelvis 32(2): 70-77, 2020

At final follow-up, the weighted mean visual analogue scale scores in the PRP and control groups were 2.73 and 2.27 , respectively, a difference that was not statistically significant. Similarly, other functional scores (e.g., HOSADL, HOS-SSS, NAHS) were reported by two included studies with weighted mean scores of $80.55,67.09$ and 78.99 , respectively in the PRP groups and mean scores of $83.68,69.55$, and 81.24 , respectively in the comparison control groups; no significant differences were observed (Table 3).

\section{Complications}

Only one study (Redmond et al. ${ }^{177}$ ) reported complications in terms of revision surgery; 35 patients (11.4\%) underwent revision procedures following hip arthroscopy in the form of revision hip arthroscopy $(\mathrm{n}=24)$ or total hip arthroplasty $(n=13)$.

\section{Risk of bias}

The Cochrane risk of bias tool revealed that the Redmond

Table 3. Result of VAS and mHHS

\begin{tabular}{lccc}
\hline \hline & \multicolumn{3}{c}{ Study } \\
\cline { 2 - 4 } & Rafols et al. [16] (2015) & Redmond et al. [17] (2015) & LaFrance et al. [18] (2015) \\
\hline VAS & & & - \\
Preoperative & $5.04(5-8)$ & 5.6 & - \\
3-month & $1.22(1-4)$ & 2.62 & - \\
Latest & $0.71(0-3)$ & 3.36 & 51.9 \\
mHHS & $70.79(50-80)$ & 62.8 & 77 \\
Preoperative & $91.79(85-95)$ & 82.1 & 75.9 \\
3-month & $94.8(90-98)$ & 78.6 & 54.9 \\
Latest & - & 58.0 & 74.1 \\
NAHS & - & 76.6 & 82.0 \\
Preoperative & - & 78.3 & \\
3-month & & & 59.1 \\
Latest & - & 68.2 & 79.0 \\
HOS-ADL & - & 83.9 & 84.1 \\
Preoprative & - & 82.9 & \\
3-month & & & \\
Latest & & & \\
\hline
\end{tabular}

Values are presented as mean (range) or mean only.

VAS: visual analogur scale, mHHS: modified Harris hip score, NAHS: non-arthritic hip score, HOS-ADL: hip outcome scoreactivities of daily living.

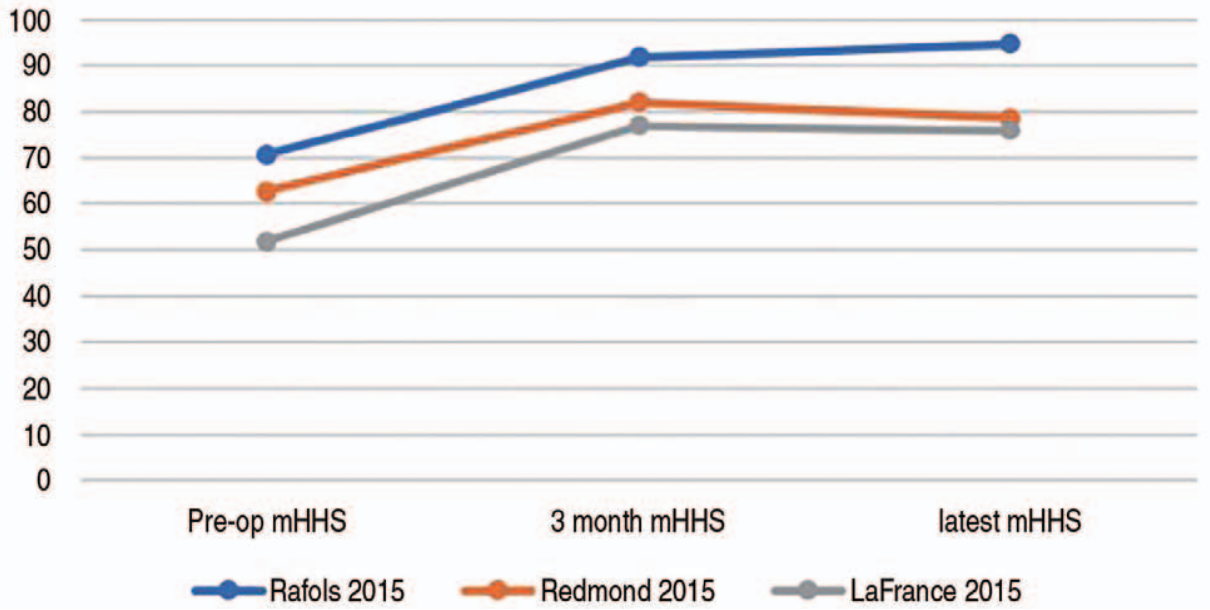

Fig. 2. The results of modified Harris hip score (mHHS). 


\section{Hip \& Pelvis}

Mohammed Ali et al. Does PRP Augmentation Following Hip Arthroscopy Improve Outcomes

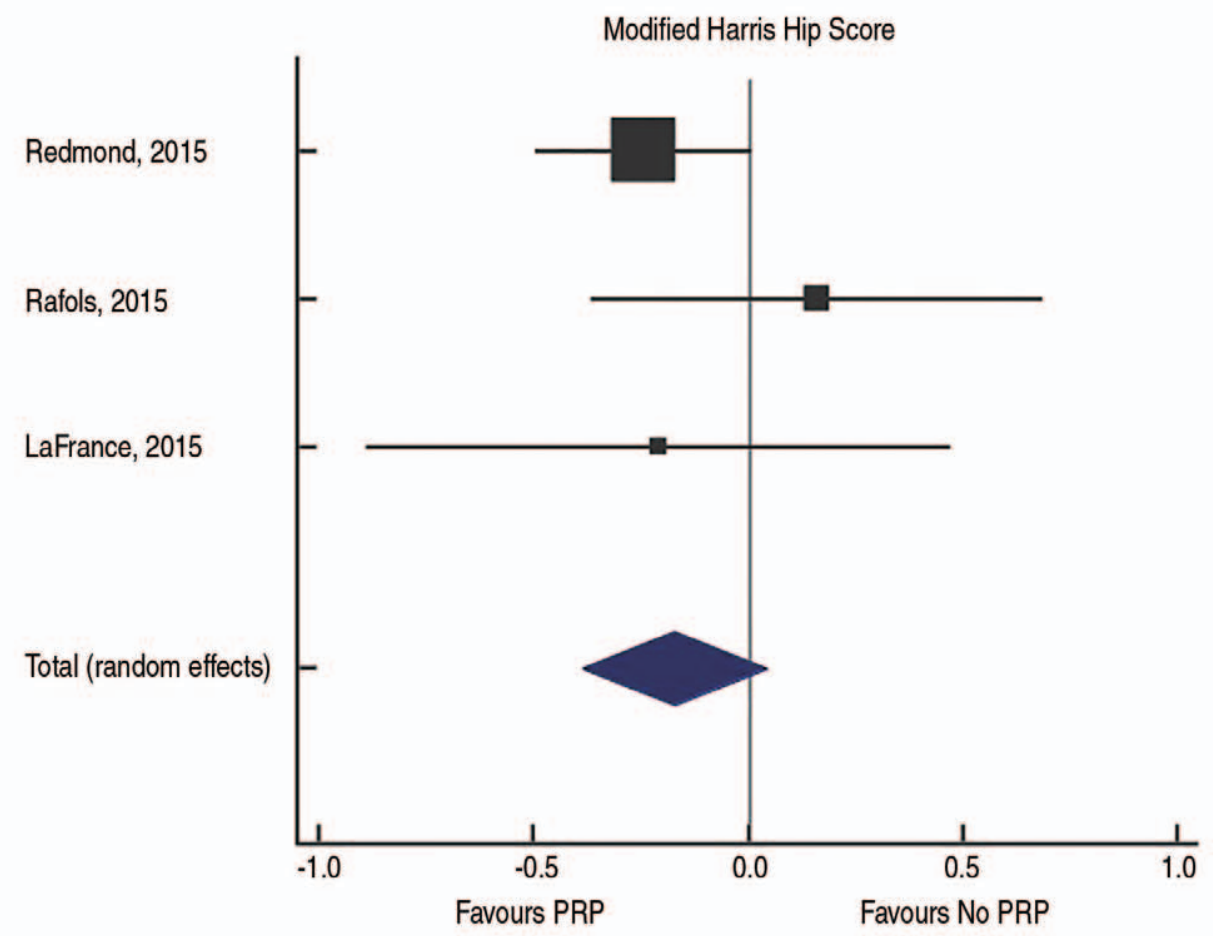

Fig. 3. Forest plot.

PRP: platelet-rich plasma.

\begin{tabular}{|l|c|c|c|}
\hline & Rafols 2015 & Redmond 2015 & Lafrance 2015 \\
\hline Random sequence generation & + & - & + \\
\hline Allocation concealment & + & - & + \\
\hline Blinding of participants and personnel & + & $?$ & + \\
\hline Blinding of outcome assessment & $?$ & + & + \\
\hline Incomplete outcome data addressed & - & + & + \\
\hline free of selective reporting & + & + & - \\
\hline No other bias & - & & + \\
\hline
\end{tabular}

\section{Yes $(+)$}

No (-)

Uncertain (?)

Fig. 4. Quality assessment of included articles. 
et al. ${ }^{17)}$ paper has a high risk of bias while the Rafols et al. ${ }^{16)}$ and LaFrance et al. ${ }^{18)}$ publications had a low bias risk (Fig. 4).

\section{DISCUSSION}

PRP has been used for varied intra-articular hip pathologies to promote healing and improve outcomes of hip arthroscopy. In this review we note that the use of PRP treatment following hip arthroscopy is of limited value based on the reported outcome scores.

Modified Harris hip score was reported in all three included studies with varying results. Though Rafols et al. ${ }^{16)}$ noted better modified Harris hip score at final followup in the PRP group, this difference was not statistically significant. On the contrary, LaFrance et al. ${ }^{18)}$ observed improved modified Harris hip score outcome scores in the control group compared to the PRP group; once again, this difference was not statistically significant. However, Redmond et al. ${ }^{17)}$ in their comparison between PRP and bupivacaine reported statistically significantly better modified Harris hip score outcome scores for the PRP group compared with the bupivacaine group. Similarly, HOS-ADL and HOS-SSS reported in two studies under review $^{17,18)}$ were not significantly different between the two groups. The NAHS outcome scores of the PRP group were improved compared with control groups in one study ${ }^{18)}$, while it was better (although without significance) in the bupivacaine group in the other study ${ }^{17}$. Thus, review of the three studies in terms of functional scores following PRP injection post hip arthroscopy did not demonstrate any clear benefits when compared to control groups.

Visual analogue scale scores were described by two of the included studies ${ }^{16,17)}$. Rafols et al. ${ }^{16)}$ noted significantly better visual analogue scale score in patients receiving PRP injections following hip arthroscopy, specifically in the initial 48 hours post-surgery. The visual analogue scale score at final follow-up was also better in the PRP group, however this difference was not statistically significant. On the other hand, the study by Redmond et al. ${ }^{17)}$ measured visual analogue scale at three months and two years postoperatively with better results in the bupivacaine group. The difference between the two studies might be related to use of bupivacaine, which may have provided better pain relief.

Several techniques have been adopted to prepare PRP; there is currently no standardization of preparation or use. Subsequently, different techniques yield different platelet concentrations and may produce products with varying biology, amount and type of growth factors, and potential uses. In a review by Redmond et al. ${ }^{17)}$, a relatively low platelet concentrate (compared with Rafols et al. ${ }^{16)}$ and LaFrance et al. ${ }^{18)}$ ) was used with no leukocytes, and their results did not demonstrate a benefit to using PRP. LaFrance et al. ${ }^{18)}$ had slightly increased leukocyte counts over baseline; their study concluded that PRP did not lead to differences outcomes of hip arthroscopy. On the other hand, Rafols et al. ${ }^{16)}$ used a leukocyte-rich PRP (Lr-PRP) and had encouraging results. The different PRP preparations and the possibility of exerting different therapeutic effects have been previously investigated in vitro by Yan et al. ${ }^{22)}$ who compared the effects of the intratendinous injection of leukocyte-poor PRP (Lp-PRP) vs. Lr-PRP in a rabbit chronic tendinopathy model. They concluded that Lp-PRP is superior to Lr-PRP as it improves tendon healing and is a preferable option for the clinical treatment of tendinopathy. Another study by Zhou et al. ${ }^{23)}$ noted that while both LrPRP and Lp-PRP appear to be safe in inducing differentiation of tendon stem cells into active tenocytes, Lr-PRP may be disadvantageous to the healing of injured tendons because it produces catabolic and inflammatory effects on tendon cells.

Rafols et al. ${ }^{16)}$ assessed joint effusion following hip arthroscopy using magnetic resonance imaging scans at six months; they reported no effusion in $36.7 \%$ of patients in the PRP group vs. $21.1 \%$ in the control group, a difference that was statistically significant $(P=0.013)$. However, considering labral integration, they found no statistical differences between the groups $(P=0.76)$. Accordingly, they concluded that although PRP can reduce postoperative inflammation, the long-term clinical benefit of PRP was not unclear. LaFrance et al. ${ }^{18)}$ studied bruising and swelling in the postoperative period as a marker of inflammation. There was no significant difference in change in thigh circumference between the two groups, however the placebo group had a much higher incidence of postoperative ecchymosis compared to the PRP group $(P=0.005)$. Redmond et al. ${ }^{17)}$ reported outcomes at three months and two years, with no evaluation in immediate postoperative period, and thus might have missed the beneficial effects of PRP in the initial stages of postoperative recovery.

This review is limited by the quality of the three primary studies reviewed; one was a quasi-randomized trial with random allocation to the group by operating-room schedule (vs. true randomization). Additionally, objective measures of labral healing were not used uniformly across the three studies, a variation which limited the ability to assess 
the effect of PRP following hip arthroscopy. This review also included only three studies and a total of 141 patients. Limiting the search to only publications written in English may have limited inclusion of other potentially relevant studies. Furthermore, limiting inclusion to only results from published studies might have introduced publication bias.

\section{CONCLUSION}

Although treatment with PRP appears to be well tolerated following hip arthroscopy, the evidence from this review suggests that it did not significantly improve postoperative functional outcomes when compared to control groups.

\section{CONFLICT OF INTEREST}

The authors declare that there is no potential conflict of interest relevant to this article.

\section{REFERENCES}

1. Freeman CR, Azzam MG, Leunig M. Hip preservation surgery: surgical care for femoroacetabular impingement and the possibility of preventing hip osteoarthritis. J Hip Preserv Surg. 2014;1:46-55.

2. McCarthy JC, Jarrett BT, Ojeifo O, Lee JA, Bragdon CR. What factors influence long-term survivorship after hip arthroscopy? Clin Orthop Relat Res. 2011;469:362-71.

3. Guadilla J, Fiz N, Andia I, Sánchez M. Arthroscopic management and platelet-rich plasma therapy for avascular necrosis of the hip. Knee Surg Sports Traumatol Arthrosc. 2012;20:393-8.

4. Sun Y, Feng Y, Zhang CQ, Chen SB, Cheng XG. The regenerative effect of platelet-rich plasma on healing in large osteochondral defects. Int Orthop. 2010;34:589-97.

5. Kraeutler MJ, Garabekyan T, Mei-Dan O. The use of platelet-rich plasma to augment conservative and surgical treatment of hip and pelvic disorders. Muscles Ligaments Tendons J. 2016;6:410-9.

6. Alsousou J, Thompson M, Hulley P, Noble A, Willett K. The biology of platelet-rich plasma and its application in trauma and orthopaedic surgery: a review of the literature. J Bone Joint Surg Br. 2009;91:987-96.

7. De Pascale MR, Sommese L, Casamassimi A, Napoli C. Platelet derivatives in regenerative medicine: an update. Transfus Med Rev. 2015;29:52-61.

8. Sengodan VC, Kurian S, Ramasamy R. Treatment of partial rotator cuff tear with ultrasound-guided platelet-rich plasma. J Clin Imaging Sci. 2017;7:32.

9. Randelli PS, Arrigoni P, Cabitza P, Volpi P, Maffulli N.
Autologous platelet rich plasma for arthroscopic rotator cuff repair. A pilot study. Disabil Rehabil. 2008;30:1584-9.

10.Zayni R, Thaunat M, Fayard JM, et al. Platelet-rich plasma as a treatment for chronic patellar tendinopathy: comparison of a single versus two consecutive injections. Muscles Ligaments Tendons J. 2015;5:92-8.

11. Dhillon MS, Patel S, John R. PRP in OA knee - update, current confusions and future options. SICOT J. 2017;3:27.

12. Varshney A, Maheshwari R, Juyal A, Agrawal A, Hayer P. Autologous platelet-rich plasma versus corticosteroid in the management of elbow epicondylitis: a randomized study. Int J Appl Basic Med Res. 2017;7:125-8.

13. Mei-Dan O, Carmont MR, Laver L, Mann G, Maffulli N, Nyska M. Platelet-rich plasma or hyaluronate in the management of osteochondral lesions of the talus. Am J Sports Med. 2012;40:534-41.

14. Vavken P, Murray MM. The potential for primary repair of the ACL. Sports Med Arthrosc Rev. 2011;19:44-9.

15. Sánchez M, Guadilla J, Fiz N, Andia I. Ultrasound-guided platelet-rich plasma injections for the treatment of osteoarthritis of the hip. Rheumatology (Oxford). 2012;51:144-50.

16. Rafols C, Monckeberg JE, Numair J, Botello J, Rosales J. Platelet-rich plasma augmentation of arthroscopic hip surgery for femoroacetabular impingement: a prospective study with 24-month follow-up. Arthroscopy. 2015;31:1886-92.

17. Redmond JM, Gupta A, Stake CE, Hammarstedt JE, Finch NA, Domb BG. Clinical results of hip arthroscopy for labral tears: a comparison between intraoperative platelet-rich plasma and bupivacaine injection. Arthroscopy. 2015;31: 445-53.

18. LaFrance R, Kenney R, Giordano B, Mohr K, Cabrera J, Snibbe J. The effect of platelet enriched plasma on clinical outcomes in patients with femoroacetabular impingement following arthroscopic labral repair and femoral neck osteoplasty. J Hip Preserv Surg. 2015;2:158-63.

19. Moher D, Liberati A, Tetzlaff J, Altman DG; PRISMA Group. Preferred reporting items for systematic reviews and metaanalyses: the PRISMA statement. PLoS Med. 2009;6: el000097.

20. Higgins JP, Altman DG, Gøtzsche PC, et al. The Cochrane Collaboration's tool for assessing risk of bias in randomised trials. BMJ. 2011;343:d5928.

21. Higgins JPT, Green S. Cochrane handbook for systematic reviews of interventions version 5.1.0. Oxford: The Cochrane Collaboration; 2011.

22. Yan R, Gu Y, Ran J, et al. Intratendon delivery of leukocytepoor platelet-rich plasma improves healing compared with leukocyte-rich platelet-rich plasma in a rabbit achilles tendinopathy model. Am J Sports Med. 2017;45:1909-20.

23. Zhou Y, Zhang J, Wu H, Hogan MV, Wang JH. The differential effects of leukocyte-containing and pure platelet-rich plasma (PRP) on tendon stem/progenitor cells - implications of PRP application for the clinical treatment of tendon injuries. Stem Cell Res Ther. 2015;6:173. 